IZA DP No. 7997

Culture and Household Decision Making:

Balance of Power and Labor Supply Choices

of US-born and Foreign-born Couples

Sonia Oreffice

February 2014 


\title{
Culture and Household Decision Making: Balance of Power and Labor Supply Choices of US-born and Foreign-born Couples
}

\author{
Sonia Oreffice \\ University of Surrey \\ and IZA
}

\author{
Discussion Paper No. 7997 \\ February 2014
}

IZA
P.O. Box 7240
53072 Bonn
Germany

Phone: +49-228-3894-0

Fax: +49-228-3894-180

E-mail: iza@iza.org

\begin{abstract}
Any opinions expressed here are those of the author(s) and not those of IZA. Research published in this series may include views on policy, but the institute itself takes no institutional policy positions. The IZA research network is committed to the IZA Guiding Principles of Research Integrity.

The Institute for the Study of Labor (IZA) in Bonn is a local and virtual international research center and a place of communication between science, politics and business. IZA is an independent nonprofit organization supported by Deutsche Post Foundation. The center is associated with the University of Bonn and offers a stimulating research environment through its international network, workshops and conferences, data service, project support, research visits and doctoral program. IZA engages in (i) original and internationally competitive research in all fields of labor economics, (ii) development of policy concepts, and (iii) dissemination of research results and concepts to the interested public.
\end{abstract}

IZA Discussion Papers often represent preliminary work and are circulated to encourage discussion. Citation of such a paper should account for its provisional character. A revised version may be available directly from the author. 
IZA Discussion Paper No. 7997

February 2014

\section{ABSTRACT \\ Culture and Household Decision Making: Balance of Power and Labor Supply Choices of US-born and Foreign-born Couples}

This study investigates how spouses' cultural backgrounds mediate the role of intrahousehold bargaining in the labor supply decisions of foreign-born and US-born couples, in a collective-household framework. Using data from the 2000 US Census, I show that the hours worked by US-born couples, and by those foreign-born coming from countries with gender roles similar to the US, are significantly related to common bargaining power forces such as differences between spouses in age and non-labor income, controlling for both spouses' demographic and socioeconomic characteristics. Households whose culture of origin supports strict and unequal gender roles do not exhibit any association of these power factors with their labor supply decisions. This cultural asymmetry suggests that spousal attributes are assessed differently across couples within the US, and that how spouses make use of their outside opportunities and economic and institutional environment may depend on their ethnicities.

JEL Classification: D1, J15, J22

Keywords: culture, gender roles, household bargaining power, labor supply

Corresponding author:

Sonia Oreffice

School of Economics

University of Surrey

Guildford, Surrey, GU2 7XH

United Kingdom

E-mail: s.oreffice@surrey.ac.uk

\footnotetext{
* Financial support from the Spanish Ministry of Science and Innovation (ECO 2011-29751) and IVIE is acknowledged. I would like to thank the editor, two anonymous referees, and seminar participants at RES 2013 and Alicante for their helpful comments. Any errors are mine.
} 


\section{Introduction}

This paper examines the labor supply choices of foreign-born and US-born couples in order to explore the role of spousal cultural background on the extent to which bargaining power forces matter in household decisions, using data from the 2000 US Census. Specifically, it investigates whether spouses who live in the US but are from different ethnicities relate heterogeneously to bargaining power forces, as measured by discrepancies in spouses' ages and non-labor income, within a collective household labor supply framework.

The phenomena of immigrants' labor market outcomes and the influence of their cultural background on one side, and intra-household bargaining power and household decision-making on the other, have been widely studied in the literature. A large body of theoretical and empirical literature shows that the intra-household distribution of power influences households' outcomes in both developing and developed countries (Chiappori, Fortin, Lacroix, 2002; GrossbardShechtman, 1993; Lundberg and Pollak, 1996; Thomas, 1990). In particular, the collective household behavior model predicts that household members make Pareto-efficient decisions according to their respective bargaining power positions, which in turn depend on outside opportunities and social and legal factors, such as members' relative share of non-labor income, their age differences, their body mass index, abortion and divorce laws, and sex ratios (Browning, Bourguignon, Chiappori, Lechene, 1994; Chiappori et al., 2002; Negrusa and Oreffice, 2010; Oreffice, 2007; Oreffice, 2011; Oreffice and Quintana-Domeque, 2012).

There is empirical evidence of these bargaining power effects concerning various countries, from different cultures and parts of the world (Grossbard and Amuedo-Dorantes, 2007; Lundberg, Pollak, Wales, 1996; Rangel, 2006; Schultz, 1990; Thomas, 1990). While all these empirical studies have focused on a single country, Datta Gupta and Stratton (2010) present a two-country analysis on US and Denmark, and argue that different social norms across countries can affect intra-household bargaining power, mitigating or reinforcing the bargaining effect on couples' decisions concerning leisure and labor supply. Still, no emphasis has been devoted to differences across ethnicities within a country, and the recent immigration waves throughout Europe and the US, along with the sizable presence in the US of immigrants from a variety of cultural backgrounds, prompt to explore the role of intra-household bargaining power by culture and spouses’ gender role beliefs. 
A recent strand of literature specifically emphasizes the role of culture and family experience on economic outcomes such as female labor force participation and fertility choices, and on the marriage market. Fernandez and Fogli (2006, 2009), Fernandez (2007), and Blau, Kahn, and Papps (2011) show that culture, as measured by female labor force participation rate and total fertility in country of origin, explains fertility and labor market choices of American women living in the US but born from foreign parents, while male labor supply is not affected by the country of origin. Using the same US Census data and the same sources of variation for cultural differences such as country of origin, length of stay in the US, and linguistic distance, related literature studies the determinants of interethnic marriages and living arrangements (e.g., Angrist, 2002; Chiswick and Houseworth, 2010; Giuliano, 2007). In particular, Giuliano (2007) emphasizes the importance of analyzing the role of culture in a "neutral environment", using samples drawn from the population of only one country. Finally, culture and immigration have also been linked to labor market activity and the extent of wage and employment consequences for native and foreign-born workers.

All these studies highlight that the main challenge in this line of research is to disentangle culture from institutional and traditional economic variables such as prices and income. Indeed, this paper addresses this feature using one large data set such as the US Census, with US- and foreign-born individuals from a large variety of countries at different stages of development and assessment of gender roles in society, who live and work in the US, facing the same institutions and bargaining power measures. Specifically, the cultural mechanism through which intrahousehold bargaining power and couples' labor supplies may be related is analyzed here using the five-percent national random sample of the 2000 US Census data on married men and women.

The US Census data provide the largest sample of households with foreign-born spouses, their detailed ethnic, demographic, labor and income information, along with standard samples of US-born individuals. The degree of cultural differences from the US mainstream is captured by the country of birth of each spouse, to which the information on the corresponding measures of gender roles is associated. Following the definition of culture offered by Fernandez (2007), I consider culture as a set of beliefs and preferences, which are important determinants of behavior. The cultural proxies of both the husband and the wife are analyzed, as the husband's culture may be important in driving work decisions and household responsiveness to bargaining 
power forces (Fernandez and Fogli, 2009). I then follow a procedure in line with Guiso et al. (2008) to assess countries' cultural similarity to the US in terms of gender roles.

The focus is on first-generation immigrants, who are less likely to have assimilated and mitigated their culture and beliefs to the US mainstream, to better capture the corresponding bargaining power disparities at stake. Individuals in the sample face the same markets and institutions by construction, so that only the belief and preference components (the cultural components) are potentially relevant. The main assumption here is that immigrants bring with them some of the attitudes of their country of origin (Carroll, Rhee, and Rhee, 1994). Then, since they differ by their own cultural heritage, it is still possible to estimate the impact of cultural differences on a common set of variables, as such eliminating unobserved heterogeneity and comparability concerns which would result from cross-country estimation from separate data sets. As additional evidence, second- and higher-generation immigrants are considered using the information on primary ancestry, examining US-born spouses whose culture may differ by ancestry rather than by country of birth.

The analysis here considers the differences in age and non-labor income ownership between spouses, two commonly used indicators of intra-household bargaining power. According to Chiappori et al. (2002), when a spouse has a relatively better attribute (relatively older or richer), the distribution of gains from the relationship would shift in his/her favor, generating opposite income effects on the spouses, which are testable on their labor supplies. Consequently, the spouse with a more favorable bargaining position would decrease his/her hours worked, while his/her mate would increase his/hers.

My identification strategy consists of estimating the associations of intra-household age and non-labor income gaps with the labor supplies of both spouses, comparing their hours of work cross-sectionally among US-born and foreign-born couples with various extents of cultural disparities to the US in terms of gender roles. Specifically, I test whether there is a stronger association for those married individuals whose cultural background supports more egalitarian gender roles, and no association at all for couples with very different gender role norms from the US. Therefore, this study considers individuals who are already married to men and women of their same cultural background, leaving aside the interesting patterns of intermarriage or sorting by ethnicity, which have recently been empirically analyzed in Furtado (2012), for instance. 
The empirical analysis shows that the hours worked by US-born spouses are more responsive to the differences between spouses in age and non-labor income, than those by foreign-born couples whose country of origin supports a traditional role of women. In US-born couples, and in those coming from countries with gender roles similar to the US ${ }^{1}$, a relatively older, or richer spouse supplies less labor, the opposite holding for his/her mate, controlling for both spouses' demographic and socioeconomic characteristics. This evidence on both spouses' labor supplies, and the signs of the estimated coefficients, is consistent with the household bargaining power interpretation. Interestingly, households whose culture of origin is quite or somewhat different on gender role grounds than the US do not exhibit any relationship between this measured balance of power and their labor supply decisions.

A 5-year difference implies working about 12 hours less, and 5,000 dollars more of nonlabor income relative to their wives implies about 9 hours less. For wives, the corresponding figures are 8 and 50 hours more. While the foreign-born couples culturally distant from the US do not exhibit any significant association with these bargaining forces, those immigrant households with very similar culture to the US show a significant association with these bargaining power factors for both spouses: for husbands, 19 and 5 hours less, and for their wives 35 and 170 hours more, respectively. The estimated correlation of female labor supply and age difference is higher in magnitude than in the case of US-born couples. In addition, joining the sample of US- and foreign-born spouses and interacting the bargaining power variables with the gender role index associated with their country of origin provides evidence consistent with the bargaining power interpretation of the estimates on the subsamples of couples by cultural disparity from the US. I also present estimates controlling for and interacting with the number of years spent in the US by foreign-born spouses, and obtain virtually identical results.

These findings represent the first empirical evidence suggesting that spousal attributes and empowerment are assessed differently across couples within the US, and that couples' responsiveness to a common economic and institutional environment may depend on their culture of origin. The importance of this novel approach rests in providing an empirical assessment and cross-cultural comparisons which may be useful to devise public policies targeting immigrant households and women in particular. They may be the ones least likely to

\footnotetext{
${ }^{1}$ The similarity of institutions is defined according to the country of origin, and categorized in the three groups "very similar", “somewhat similar”, and “different” from the US culture, as explained in Section 3.
} 
respond and take advantage of an "empowerment” policy, because of their cultural background “constraining” them to ignore outside opportunities and welfare enhancement measures.

The paper is organized as follows. Section 2 describes the theoretical framework and Section 3 the empirical specification and the data. Section 4 presents the empirical results, and discusses the sensitivity analysis and potential alternative explanations. Finally, Section 5 concludes the paper.

\section{Theoretical framework}

The collective household labor supply model with distribution factors (Chiappori et al., 2002) is applied to US-born and foreign-born couples with different degrees of cultural disparities with respect to the US, and thus with a potentially different responsiveness to bargaining power forces. A household is composed of two decision makers, husband and wife, each having a distinct utility function on consumption and leisure, and making Pareto-efficient decisions. Preferences are egoistic, in that one mate's utility does not depend on the other's consumption or leisure, although the model can be extended to allow for caring preferences and public goods. Let $\mathrm{h}^{i}$ and $\mathrm{C}^{i}$ for $i=h, w$ denote member $i$ 's labor supply and consumption of a private composite good (whose price is normalized to unity), $y$ the household non-labor income, $w_{i}$ the wage rate of spouse $i$, and $z_{i}$ possible preference parameters and cultural background of each spouse, such as education, race, or country of birth. Finally, let $s_{1}$ and $s_{2}$ represent the two distribution factors (bargaining power forces) under analysis: the differences between spouses in non-labor income and age. The utility function of member $i=h, w$ is $U^{i}\left(1-h^{i}, C^{i}\right)$, where $U$ is strictly quasi-concave, increasing, and continuously differentiable, while, following convention, the utility from companionship is assumed to be separable and not to influence the trade-off between leisure and consumption.

The optimal allocations of labor supply of each spouse are determined by the following program:

$\max _{h^{h}, C^{h}} U^{h}\left(1-h^{h}, C^{h}\right)$

subject to

$C^{h} \leq \varphi\left(w_{h}, w_{w}, y, s_{1}, s_{2}, z_{h}, z_{w}\right)+w_{h} h^{h}$ 
where the spouse faces a symmetric problem. $\varphi\left(w_{h}, w_{w}, y, s_{1}, s_{2}, z_{h}, z_{w}\right)$ represents the husband's share of household non-labor income $y$, while the wife receives $y-\varphi\left(w_{h}, w_{w}, y, s_{1}, s_{2}, z_{h}, z_{w}\right)$, so that the stronger the husband's bargaining power, the higher his share of household non-labor income and the lower his wife's. The sharing rule $\varphi\left(w_{h}, w_{w}, y, s_{1}, s_{2}, z_{h}, z_{w}\right)$ is a function of prices (here normalized to unity), spouses' wages, household non-labor income, distribution factors (here the non-labor income gap and age gap) ${ }^{2}$, and other observable characteristics $\mathrm{z}$.

The couple's Pareto-efficient decisions yield the following equilibrium labor supply functions of the two spouses:

$$
\begin{aligned}
& h^{h}=h^{h}\left[w_{h}, \varphi\left(w_{h}, w_{w}, y, s_{1}, s_{2}, z_{h}, z_{w}\right)\right] \\
& h^{w}=h^{w}\left[w_{w}, y-\varphi\left(w_{h}, w_{w}, y, s_{1}, s_{2}, z_{h}, z_{w}\right)\right]
\end{aligned}
$$

The derivatives of each labor supply function with respect to the second arguments are expected to be negative, reflecting a pure income effect (leisure is commonly assumed to be a normal good). Hence, factors that strengthen the husband's bargaining power reduce the labor supplied by the husband and increase the labor supplied by the wife, ceteris paribus, in particular controlling for own wage and the couples' total non-labor income $y$. The question of whether foreign-born couples' hours of work are related to such factors in the direction predicted by the theory and already estimated for US couples in general is investigated by testing their relationship with the labor supplies of foreign-born couples from different cultural backgrounds, and comparing it to the corresponding evidence on US-born spouses.

The decisions of spouses whose country of origin supports strict gender roles and traditional family institutions relative to the US may be very weakly related to bargaining power forces. Their household behavior may reflect a setting where spousal personal characteristics and outside opportunities do not influence their household decision-making. The non-labor income difference and age differences represent relevant monetary and demographic personal attributes enhancing spouses’ outside opportunities, which have been extensively estimated to be sources of bargaining power (e.g., Browning, Chiappori, Weiss, 2014). If they did not significantly enter

\footnotetext{
2 The sex ratio, divorce laws, abortion legalization, alimony, and child benefits laws, are other examples of distribution factors that have been studied in the literature (Chiappori et al, 2002; Lundberg and Pollak, 1996; Oreffice, 2007).
} 
an immigrant couple's decision process, this would suggest that the cultural background can inhibit this mechanism and any actual intra-household bargaining, so that the labor supplies of this type of couples would not depend on these factors.

The following empirical analysis specifically tests the predictions of Chiappori et al. (2002) which were developed for married working couples. Within this framework, this study as well focuses on those couples where both individuals are working (estimation including individuals who do not work through a Heckman's sample selection model is available upon request).

\section{Empirical Specification and Data Description}

The sample under analysis consists of married couples with both spouses between 18 and 65 years of age. US-born and foreign-born spouses are identified using information on the individual place of birth, further categorizing foreign-born couples according to their specific country of origin and to whether husband and wife share the same cultural background.

Spouses are defined to share the same cultural background if they are from the same country of origin, or from different countries of origin provided that these are characterized by similar prevailing beliefs in terms of gender roles. To establish these comparisons, I follow a similar procedure to Carroll et al. (1994) and Antecol (2000), who identify sets of countries where the prevailing beliefs are comparable to the US ones, and others where they are different, assuming that there are cultural similarities among the countries of each of these groups. More refined groups of countries are used here than in Carroll et al. (1994) and more measures of gender roles are considered than in Antecol (2000) or Carroll et al. (1994), in line with Guiso et al. (2008). Specifically, I first considered four variables used in the literature as possible measures of gender roles across countries: the gender gap index, the political empowerment index, the female economic activity rate such as the female labor force participation rate and the ratio of female to male labor force participation rate (age 15 and above), and the human development index ${ }^{3}$. To create a variable that successfully captures variation in the underlying gender roles across countries, I then confined the analysis to the gender gap variable and the

\footnotetext{
${ }^{3}$ The first three variables are explicitly used by Guiso et al. (2008) and they all come from the same sources: the Global Gender Gap report by the World Economic Forum (for the first two), and the International Labour Organization (ILO) (for the other three measures). I use the year 2006 for all variables since the first two are not available in earlier years. The first two are defined as ordinal rankings across countries, and the last three have been translated into rankings to make them comparable to the other variables.
} 
political index, making these variables the preferred components of the gender role index constructed by principal component analysis. This approach of reducing the dimensionality of these measures into their common component is supported by the large Cronbach's alpha reliability coefficient ${ }^{4}$.

This constructed gender role variable captures the underlying common component of gender roles across countries, and is used to divide the observations of married couples into three groups: those whose country of origin have gender roles very similar to the US, i.e., those with very similar cultural background to the US, those with somewhat similar gender roles; those with very different cultural background from the US. There are 115 countries for which the World Economic Forum data on gender role measures were collected in 2006 and for which the above gender role variable has been created, and for 89 of them the US Census records the detailed birthplace country code in the year 2000. These are divided as follows to create the three groups of couples by country of origin in terms of the constructed gender role index. Countries with culture very different from the US: Saudi Arabia, Yemen, Egypt, Iran, Algeria, Turkey, Jordan, Morocco, Kuwait, Nigeria, Pakistan, Malaysia, Italy, Greece, South Korea, Japan, Chile, Albania, Hungary, Cyprus, Guatemala, Uruguay, India, Nepal, Mexico, Honduras, Cameroon, Ukraine, Russia. Countries with culture somewhat different from the US: Indonesia, Romania, France, Kenya, Singapore, Uzbekistan, Cambodia, Slovakia, Brazil, Czech Republic, Ecuador, Poland, Bolivia, Venezuela, Nicaragua, Dominican Republic, Ethiopia, Georgia, Moldova, Ghana, Macedonia, Thailand, Paraguay, El Salvador, Bangladesh, Panama, Bulgaria, Trinidad and Tobago, Zimbabwe, Israel, Argentina, Costa Rica, China. Countries with very similar culture to the US: Sweden, Norway, Finland, New Zealand, Denmark, Tanzania, Netherlands, United Kingdom, Germany, Canada, Ireland, Uganda, Australia, Switzerland, Philippines, Austria, Spain, Latvia, Colombia, South Africa, Portugal, Croatia, Sri Lanka, Lithuania, Belgium, Jamaica, Peru. This "full dummy controls" approach does not impose any restrictions on the influence of the country of birth, whereas specifications with female labor force participation or total fertility rates would, so that the former method is preferred here (e.g.,

\footnotetext{
${ }^{4}$ A test scale of 0.83 is achieved. Guiso et al. (2008) use these measures separately and alternatively, and do show that the labor force participation measure has a lower correlation to the others. They focus on 40 countries, 30 of which are OECD countries, no African or Middle Eastern country, and very few from Central and Latin America, whereas this analysis considers countries in all the five continents, in which female labor force participation rate can be high also with uneven gender roles (several African sub-Saharan countries, for instance). Fortin (2005) also uses only 30 countries, none of which from Africa, Asia, or South America.
} 
Antecol, 2000 for a discussion of this advantage). Couples of US-born spouses are restricted to non-Hispanic whites, to hold a uniform reference group representing US culture.

The focus is on first-generation immigrants: on one hand, a differential impact of bargaining power forces should be more pronounced for those who actually were born and spent some time in a country different from the US, since recent immigrants are less likely to have assimilated and mitigated their culture and beliefs to the US mainstream (Antecol, 2000). On the other hand, it is not possible after 1970 to exactly identify either parent's country of birth in the US Census, and therefore the information of primary ancestry is used, thus making it impossible to distinguish second-generation from higher-generation immigrants in the US Census (Fernandez and Fogli, 2009). In addition, several observations have a non-reported or unreadable ancestry, and several ancestries that would have a corresponding value for the gender role index are instead not available in the 2000 US Census. Therefore, a direct comparison in terms of assimilation using the evidence from first- and second and above-generation immigrants cannot be completely established due to the different origins and composition of the present and past immigration $^{5}$.

It is crucial to the empirical analysis that the individuals in the sample face the same markets and institutions, and that it is possible to estimate the impact of cultural differences on a common set of variables, since they may differ by their own and/or their spouses' cultural heritage, as such eliminating unobserved heterogeneity and comparability concerns which would result from cross-country estimation from separate data sets (Fortin, 2005). Many cross-country differences in the economic environment are difficult to capture with aggregate statistics, so that cross-country analyses may fail because of mis-measuring or omitting important variables. The advantage of using US Census household level data from a single country is that all the immigrants face the same economic environment and institutions. Also, within-country studies provide better controls for human capital and labor factors, such as education (Antecol, 2000).

Estimation is carried out on the US Census data for the year 2000, specifically its fivepercent sample "5\% IPUMS data" (1-in-20 national random sample of the population), which provides the largest sample of households with foreign-born spouses, their detailed ethnic, demographic, labor and income information, along with standard samples of US-born

\footnotetext{
${ }^{5}$ Evidence on the association of bargaining power and hours of work using spouses' primary ancestry instead of country of birth to define cultural background will be presented in Section 4.2.
} 
individuals. These data allow to identify the country of birth of household members ("birthplace" detailed code), their ancestry, along with the number of years already spent living in the US. Country of birth is considered a more robust measure than ancestry (e.g., Chiswick and Houseworth, 2011), and is necessary to identify first-generation immigrants in the US Census 2000.

Specifically, a random sample (50 percent) of married "heads" and "spouses" were extracted from the Census using the variables "relationship to household head" and "marital status'. Records in these files were then matched on the household identification code "serial" to create a single observation for each couple. Using the variable "sex", couples with the head being the husband were then identified with a dummy variable index, and individuals sorted into husbands and wives. The Census defines the head as the individual who owns the housing unit or signs the rental contract, and the partner/spouse is the individual who identifies himself/herself as such. Individuals with imputed values for sex, marital status, relationship to household head and country of origin were excluded from the main samples (about $1 \%$ of observations are dropped). This method prevents couples from being misclassified, in particular in terms of cultural background. Only couples where both the head and the spouse are actually present are considered, while I exclude households where there are multiple spouses, or more than two adults. Moreover, excluded from the sample are all individuals in school, in the military, in farm households, or not working. Individual weights are used to make the sample representative of the US population and economy.

The following labor supply equations are estimated for husbands and wives, and run separately on each type of couples, US-born, foreign-born, and foreign-born divided into the three above categories reflecting different degrees of cultural similarity to the US:

$$
\begin{aligned}
& h^{h}=\alpha_{1} \ln w^{h}+\alpha_{2} \ln w^{w}+\alpha_{3} y+\gamma_{1} y_{-} \text {diff }+\gamma_{2} \text { age_diff }+\delta X+\varepsilon^{h} \\
& h^{w}=\beta_{1} \ln w^{h}+\beta_{2} \ln w^{w}+\beta_{3} y+\lambda_{1} y_{-} \text {diff }+\lambda_{2} a g e_{-} \text {diff }+\psi X+\varepsilon^{w}
\end{aligned}
$$

where the dependent variable is total annual hours worked in the previous year, and $y_{-}$diff and age_diff are the two bargaining power factors under consideration. The former is defined as the husband's total non-labor income in dollars minus the wife's total non-labor income in dollars, while the latter as the husband's age in years minus the wife's age in years. Both the individual non-labor income and age variables do not have any missing values and their differences can be 
either positive or negative, or zero ${ }^{6}$. In the Census, the age and all the income questions are asked to each adult in the household, so that their measures are self-reported, rather than reported by a proxy respondent.

The identification strategy of these bargaining power factors consists of estimating $\gamma_{1}$ and $\gamma_{2}$ for husbands, and $\lambda_{1}$ and $\lambda_{2}$ for wives and comparing these estimates across couples with different cultural backgrounds. The role of the non-labor income difference on the labor supply of husbands and wives is captured by $\gamma_{1}$ and $\lambda_{1}$. According to the collective labor supply framework, if a spouse is relatively richer, then his/her labor supply should be lower and the labor supply of his/her mate should be higher than in other households without this income disparity. Hence, $\gamma_{1}$ should be negative, while $\lambda_{1}$ should be positive. The corresponding coefficients for age difference are $\gamma_{2}$ and $\lambda_{2}$. If being relatively older is a favorable attribute associated to higher intra-household bargaining power, so that the older spouse's labor supply should be lower and the labor supply of his/her mate should be higher than in the absence of this age gap, then $\gamma_{2}$ should be negative and $\lambda_{2}$ positive.

The other regressors are the logarithm of the hourly wage rate $w^{i}$ of each spouse $i=h, w$, the couple's total non-labor income $y^{7}$, and a vector of covariates $X . X$ includes education of each spouse (number of completed years of schooling), number of each spouse's own children living in the household, and only own age of spouse $i$, so that the impact of age_diff can be identified. Dummy variables for racial profiles are also included at the individual level. Taking into account education can eliminate the indirect effect that culture may have on spouses' labor supply choices, as those individuals (especially women) who work in the labor market due to their cultural background are also more likely to be more educated. This aspect should not interfere with the bargaining power variables.

\footnotetext{
${ }^{6}$ The ratio of non-labor incomes and the ratio of ages were used as alternative distribution factors. However, the former is not defined for the several couples with no non-labor income, and they both introduce non-linearities in the labor supply equations.

${ }^{7}$ All wage and income variables refer to the previous year 1999. I consider individuals who are not self-employed, so that earned income coincides with wage income, and non-labor income indeed represents non-earned income sources. Results are robust to the inclusion of the self-employed (less than 10 percent of my samples).
} 
The vector $X$ also includes state fixed effects, which should capture the different labor market opportunities and social and legal attitudes toward immigrants that exist across states. ${ }^{8}$ Robust standard errors clustered by state are used to allow for correlation of household observations within state. I alternatively clustered by metropolitan area (or microdata area 'puma' or 'conspuma') ${ }^{9}$. These specifications do not use a differences-in-differences estimator: husbands' and wives’ regressions are estimated separately, across types of couples. As such, they should not suffer from the understated standard errors highlighted by Bertrand, Duflo, and Mullainathan (2004). At any rate, clustering by state (metropolitan area) should rectify any such underestimation.

[Table 1 about here]

Table 1 presents the descriptive statistics for the husbands' and wives' main variables, by type of couple. On average, married women are as educated as married men, but are younger, earn a lower wage and work fewer hours than their spouses, regardless of their US or foreignborn status. In the US-born samples, spouses are more similar in terms of age and education, while the more dissimilar to US culture, the less educated couples are. On average, the age difference is about 1.98 for US-born and 2.73 years for foreign-born ones overall, while the nonlabor income difference is around \$2,002 and \$ 1,334, respectively. Both of these differences exhibit a sizable variation in all these samples, the standard deviations being several times larger than their means.

\section{Results}

\subsection{Main evidence}

Tables 2 and 3 present the results of several regressions where the dependent variable is the husbands' or the wives’ annual hours of work, separately for couples of different cultural backgrounds.

[Tables 2 and 3 about here]

\footnotetext{
${ }^{8}$ Alternatively, I include the state unemployment rate, the state total labor force participation and female labor force participation (retrieved from the Bureau of Labor Statistics), to control for the level of economic activity in a state, and especially for employment opportunities.

${ }^{9}$ The Census reports that many metropolitan areas have only been partially identified in 2000, and that "users should not assume that the identified portion of a partly-identified metropolitan area is a representative sample of the entire metropolitan area”. Therefore, the main specifications are clustered by state.
} 
Columns 1-4 and 11-12 show a negative significant relationship of the age and income differences on the hours worked by married men, whereas for married women the coefficients are positive significant, controlling for both spouses' demographic and socioeconomic characteristics. The older or richer husbands are, the lower their labor supply and the higher the labor supply of their wives, in the overall sample, in US-born couples, and in foreign-born couples whose cultural background is very similar to the US. The older (richer) spouse may hold a more favorable bargaining position and works less, while his/her mate works more. Specifically, in US-born couples, a 5 year difference is associated to working about 12 hours less, and a 5,000 dollars more non-labor income to about 9 hours less. For wives, the corresponding figures are 8 and 50 hours more. While the foreign-born with cultural distance from the US do not exhibit any significant association with these differences (columns 7-10), those immigrant households with a cultural background very similar to the US show a significant association to these bargaining power changes: for husbands, 19 and 5 hours less, and for their wives 35 and 170 hours more. The circumstance that these married women seem more responsive to bargaining power than US-born spouses (the coefficients are statistically different), may reflect the fact that these type of immigrant couples react to changes in the environment and in outside opportunities, as shown by their decision to migrate to another country. It is important to note that there is no theoretical prediction on the significant coefficients being similar or not across groups or between spouses, and we actually observe a more similar hours response to the income difference variable than to the age difference when comparing married men to married women, and US-born to foreign-borns with similar gender role models. This could be due to different elasticities of female and male labor supplies, and/or to a different assessment of the relevance of the two bargaining power forces by foreign-born and US-born spouses.

As reported in columns 7-10, in couples whose ethnicity has a more traditional view on gender roles, spouses do not tend to work more or fewer hours according to the balance of power measures of age and income differences. The lack of significance cannot be simply due to small sample size since these "traditional" couples are much more numerous than the foreign-born couples in the other groups. This independence of their labor supply may strengthen the household-bargaining interpretation of the labor supply responses of the other groups of couples, insofar as these two specific factors are present in the household power balance, as extensively found in the literature (e.g., Browning, et al., 2014). More traditional gender role attitudes may 
prevent individuals from taking into account of or responding to balance of power incentives. Only immigrant couples whose cultural background is very similar to the US seem to be related with bargaining power forces in the direction predicted and found for US-born couples. It may also be the case that a strong disparity in cultural background is associated to more rigid labor supplies due to job type or commitment to work of these immigrants, so that the power factor measured here would not play any role along the labor supply dimension (results are robust to controlling for occupation categories).

Couples' significant relationships between these forces and labor supply are sizable, corresponding to several days of work a year. The concurrent significance on both spouses, and with opposite outcomes, is remarkable given the acknowledged rigidities in the labor supplies, and the frequency of the reported labor supply peaking around 40 hours of work per week. Traditional analyses do not emphasize changes by both spouses, let alone their labor supply responding to bargaining power forces.

No study finds that households' labor supply decisions are related to differences in nonlabor income ownership and age according to their cultural background, suggesting that they may reflect the collective household behavior of US-born couples. Moreover, the intrahousehold decision process does not appear to vary by foreign status per se, but it depends on the specific cultural views on gender roles. These findings point to married US-born and US-similar couples valuing being relatively old, controlling for wages and education of each spouse, and for individual age. This evidence is consistent with what is found in the literature, where the spouses' age difference is considered a traditional measure of bargaining power, and the older spouse has a favorable position (e.g., Browning et al., 1994; Oreffice, 2011). These findings also show that income pooling does not hold for either US-born or immigrant couples whose culture is very similar to the US. So far, the income pooling hypothesis and the prediction that bargaining power forces are irrelevant to intra-household decisions had been empirically rejected for several countries and time periods (Browning et al., 1994; Browning et al., 2014; Lundberg, Pollak, Wales, 1996; Schultz, 1990; Thomas, 1990). Instead, the evidence on those foreign-born culturally different from the US is consistent with income pooling, which may indicate a "unitary" decision-making or inefficiencies, as found occasionally in developing countries (Udry, 1996). 
As to the other covariates in the labor supply equations, most parameter estimates for all couples are comparable to the literature. In particular, the spouses' own wage response is negative significant, as is the cross-wage effects between spouses’ labor supplies. The couple's total non-labor income has a negative effect on labor supply in most regressions, while education has a positive impact, although the coefficients are not always precisely estimated. Children living in the household are associated with fewer hours of work for wives, but the opposite holds for husbands, for whom children have a positive effect on labor supply. These estimates are in line with the findings in the household labor supply literature, reported for instance in Blundell and MaCurdy (1999).

Adding own age squared and non-labor income squared to the main regressions does not alter the findings and interpretation of the bargaining power forces. Results are also robust to including the education difference between spouses along with own education (the coefficient of the education difference is not significant, as in Browning et al., 1994), to interacting education with the bargaining power variables, or to controlling for the number of years spent in the US. Adding to the main specification such a control for the accumulation of US-specific human capital, along with its interactions with the bargaining variables, does not affect the pattern of significance of the bargaining factors for the group of couples with similar culture to the US, with the other types of foreign-born couples exhibiting no significant association with these factors. As to the interaction between these factors and the amount of time in the US, the estimation yields coefficients that are basically not significant, apart from few coefficients for wives that are positive for the age difference and negative for the income differences, whereas the estimated coefficient of the number of years spent in the US is always positive and almost always significant. This is in line with the outcome variable being hours worked: better integration means also better knowledge of the characteristics of the US labor market.

[Table 4 about here]

It is important to notice that assimilation for the group of couples from similar countries to the US is not necessary for bargaining power forces: a variety of empirical studies has already documented the presence of bargaining power responses and evidence consistent with the collective model in several countries outside the US, such as Brazil, Denmark, France, the UK, etc. (see for instance Datta Gupta and Stratton, 2010). This means that the response of hours worked to bargaining power forces may not necessarily change with time spent in the US. If 
there were selection into having migrated versus remaining in country of origin, then this should make it less likely to find differences among the three groups. Migration is not necessarily a confounding factor: if migrating to the US means a stimulus toward gender parity, then people from Sweden, for instance, should be much less stimulated than people say from Bangladesh after their arrival to the US, the latter would feel much more "liberated", and may respond to bargaining power forces, but this is not what this evidence shows. Finally, allowing for the nonlinearity of the age and non-labor income differences using dummy variables constructed from the terciles of their distributions leads to estimates consistent with the main evidence shown above (estimates available upon request).

\subsection{Additional findings}

Next, I estimate the labor supply regressions on the joint sample of US- and foreign-born spouses, including the constructed gender role variable and its interactions with the bargaining forces as additional controls. Results are presented in Table 5. Table 5 clearly shows that the interaction terms exhibit the expected estimated coefficients: for the wife's regression, both interactions are negative significant, while the bargaining variables are positive significant (almost all coefficients significant at the 1\% level). The higher the gender role variable by country of origin, the farther away the country of origin is from the US culture, so that these negative coefficients are consistent with the bargaining power interpretation of these regressions: a higher value makes the coefficients of age and income differences go toward zero, since for these cultures the bargaining power impact on labor supply should be negligible. For the husband's regression, both interactions are positive, while the bargaining variables are negative significant (almost all coefficients significant at the $1 \%$ level), which is consistent with the role of this gender variable and the bargaining power interpretation.

\section{[Table 5 about here]}

These findings support the contention that bargaining power forces are associated with the intra-household allocation of resources and the hours worked by couples with no cultural disparity from the US in terms of gender roles. However, they should be interpreted with caution since these interactions assume that the gender role variable has a continuous linear relationship with cultural similarity to the US and with bargaining power, which is not warranted. The measure of gender roles has no cardinal meaning, but ordinal, and here the empirical exercise is 
trying to capture bargaining power forces and labor supplies. In addition, the interacted gender role variable refers to either the husband's or the wife's country of origin (results are robust to using either of those, or to control for both), so that this specification with interactions is not entirely equivalent to the main estimation by subsamples, since spouses are defined to share the same cultural background when they are from countries with similar gender roles with respect to the US (see Section 3).

Furthermore, as an alternative to first-generation immigrants born outside the US, second- and higher-generation immigrants are considered here using the information on primary ancestry of US-born spouses, so that now culture of origin differs by ancestry rather than by country of birth. Following, for instance, Antecol (2000) and Fernandez and Fogli (2009), the variable primary ancestry (“ancestr1”) is used to recover the information on second- and highergeneration immigrants. Since it is not possible after 1970 to exactly identify either parent's country of birth in the US Census, the information on ancestry is used, making it impossible to distinguish second-generation from higher-generation immigrants in the US Census (Fernandez and Fogli, 2009). In addition, using ancestry to determine the three groups reduces the sample size given that about $17 \%$ of the observations have a non-reported or unreadable ancestry, and several ancestries that would have a corresponding value for the gender role variable are instead not available in the 2000 US Census. However, the following subsamples can be constructed: "US ancestry" is now defined as those Americans without foreign ancestry, and "foreign ancestry" as those with it, who are then divided into the three groups according to cultural distance of their ancestry to the US by the gender role variable.

[Table 6 about here]

Table 6 reports the estimated bargaining factors' coefficients of the labor supply regressions on the various groups of couples. The table shows the significance of the bargaining power coefficients for both the US ancestry and the foreign ancestry groups: now, actually, the “foreign” group is much more numerous since it contains US-born, not foreign-borns as with first-generation immigrants. It is interesting to note that the "very different" and "somewhat different” groups are very small and exhibit non-significant coefficients (although the income coefficient is significant for husbands), while the group with "similar culture to the US" exhibits significant coefficients and is much more numerous than in the main analysis with firstgeneration immigrants (foreign-borns), reflecting on one hand the large size of the American 
population and on the other the different origins and composition of the present and past immigration. Although the results in Table 6 match the main evidence presented above, they should be interpreted with caution since a direct comparison in terms of assimilation using firstand second and above-generation immigrants cannot be completely established due to the abovementioned differences.

The estimated opposite labor supply patterns on both spouses and for both factors, and the additional empirical evidence described above are unlikely to hold unless the bargaining power explanation and the collective-household approach are correct and applicable to culture affecting household decisions. In addition, the important influence of culture on household production, marriage market matching, or divorce/remarriages cannot consistently explain the body of results of this study, as the following discussion will argue.

Cultural background and gender role models are associated with differential productivity in household production and intra-household division of labor. The labor supplies of foreignborn couples with strict gender roles may be associated with stronger household specialization and therefore be much less responsive to any bargaining power force: wives work more hours and in worse jobs to allow for the husband to make the main human capital investment (Chiswick and Houseworth, 2010) or wives work few hours in the market sector because they are devoted to household production. Also, immigrants or older US-born individuals may work less in the market because of poor local economic opportunities, or unfriendly attitudes toward immigrants. However, this study includes individuals’ wages and education, own age, and state fixed effects (and standard errors are clustered by state or metropolitan area) in the labor supply regressions, which account for the variation in labor market opportunities and attitudes. The findings are also robust to adding individual controls for occupation categories.

Culture and gender role norms also influence family formation and therefore the matching patterns of men and women in the marriage market. The literature on marital selection by differently-aged spouses shows that men and women in couples with a large age disparity are negatively selected in earnings (Mansour and McKinnish, 2014). In particular, the estimated negative coefficient on the age difference in the husbands' labor supply regressions is consistent with men being negatively selected into marriage the older they are with respect to their wives, while their wives' positive coefficient may reflect their increased labor supply in response to a match with a low earning type. It may also be the case that this marital selection is not present in 
other countries with different gender roles. However, this interpretation would not hold for the findings on non-labor income differences presented in this paper.

In the sample under analysis there are also spouses who had previously divorced and then remarried, although it is not possible to identify them in the 2000 US Census since the number of marriages or the previous divorce status are not recorded. The prevalence of remarried individuals may be relevant given the concern that divorced individuals are negatively selected on earnings. However, divorce rates and remarriage rates are significantly much higher in the US than in other countries, also than in those with similar gender roles to the US. Therefore, this negative selection hypothesis cannot explain why couples from these latter countries exhibit a significant relationship with bargaining power forces as US couples do, which holds also when interacted with education. Finally, in many countries, even more so in those with unequal gender roles, it is still common for the husband to be both older and richer, although this preference for younger women does not necessarily translate into a higher preference for leisure. According to this alternative explanation, the estimated coefficients for foreign couples with different culture from the US should be significant, and instead are not, and husbands would not exhibit a negative association between relative age and labor supply.

\section{Conclusions}

The labor supply choices of married men and women are empirically analyzed by cultural background and balance of power, using US Census data for the year 2000 on US-born and foreign-born couples according to their similarity to the US in terms of gender roles. Specifically, this paper tests whether spousal cultural backgrounds mediate the role of bargaining

power, as measured by the discrepancies in spouses' ages and non-labor income, in household decisions.

The significant negative relationship between hours worked and being the relatively older and/or richer spouse holds only for US-born couples and for those foreign-born households coming from countries with similar gender roles to the US, controlling for both spouses' demographic and socioeconomic characteristics. Interestingly, households whose culture of origin is quite different from the US, with more traditional and strict views on gender roles, do not exhibit any association between these age and income gaps and their labor supply decisions. 
These culture-asymmetric estimates suggest that spousal attributes and outside opportunities are assessed differently across couples within the US, and that their responsiveness to a common economic and institutional environment depends on their ethnicities.

This study provides the first evidence on the relationship between cultural background, bargaining power, and household labor supply, suggesting a link between ethnicity and the role of bargaining power forces in labor supply decisions, in the common institutional framework of a single large country. In this perspective, my contribution is complementary to the existing literature on household behavior (e.g., Browning et al., 2014), and also to the studies on the labor supply effects of culture (e.g., Fernandez and Fogli, 2006; Furtado, 2012). This analysis can help to devise public policies targeting immigrant households and their female members in particular, as these households may be the ones least likely to respond to family policies or to social and institutional factors due to their cultural background of strict gender roles "constraining" them to ignore outside opportunities and welfare enhancement measures. 


\section{References}

Angrist, J. (2002), “How do Sex Ratios Affect Marriage and Labor Markets? Evidence from America’s Second Generation”, Quarterly Journal of Economics, 117-3, 997-1038.

Antecol, H. (2000), “An examination of cross-country differences in the gender gap in labor force participation rates”, Labour Economics, 7, 409-426.

Blau, F., Kahn, L.M., Papps, K.L. (2011), “Gender, source country characteristics, and labor market assimiliation among immigrants”, Review of Economics and Statistics, 93-1, 43-58.

Blundell, R., MaCurdy, T. (1999), “Labor supply: a review of alternative approaches”, Handbook of Labor Economics, Elsevier, 3A , 1559-1695.

Browning, M., Chiappori, P.-A., Weiss, Y. (2014), “Family Economics”, Cambridge University Press, forthcoming.

Browning, M., Bourguignon, F., Chiappori, P.-A., Lechene, V. (1994), “Income and outcomes: a structural model of intra-household allocation”, Journal of Political Economy, 102, 1067-1096.

Carroll, C.D., Rhee, B.K., Rhee, C. (1994), “Are there cultural effects on savings? Some crosssectional evidence”, Quarterly Journal of Economics, 686-699.

Chiappori, P.-A, Fortin, B., Lacroix, G. (2002), “Marriage Market, divorce legislation, and household labor supply”, Journal of Political Economy, 110-1, 37-72.

Chiswick, B.R., Houseworth, C. (2010), “Ethnic intermarriage among immigrants: human capital and assortative mating”, Review of Economics of the Household, 9-2, 149-180.

Datta Gupta, N., Stratton, L.S. (2010), “Institutions, social norms and bargaining power: an analysis of individual leisure time in couple households", Review of Economics of the Household, 8-3, 325-343. 
Fernandez, R. (2007), "Women, work, and culture”, Journal of the European Economic Association, 5, 305-332.

Fernandez, R., Fogli, A. (2006), "Fertility: the role of culture and family experience”, Journal of the European Economic Association, 4 (2-3), 552-561.

Fernandez, R., Fogli, A. (2009), "Culture: an empirical investigation of beliefs, work and fertility”, American Economic Journal: Macroeconomics, 1-1, 146-177.

Fortin, N. (2005), “Gender role attitudes and the labor market outcomes of women across OECD countries”, Oxford Review of Economic Policy, 21-3, 416-438.

Furtado, D. (2012), “Human capital and interethnic marriage decisions”, Economic Inquiry, 501, 82-93.

Giuliano, P. (2007), “Living arrangements in Western Europe: does cultural origin matter?”, Journal of the European Economic Association, 5-5, 927-952.

Grossbard-Shechtman, S. (1993), “On the economics of marriage. A theory of marriage, labor and divorce”, Westview Press.

Guiso, L., Monte, F., Sapienza, P., Zingales, L. (2008), “Culture, gender, and math”, Science, 320, 1164-1165.

Lundberg, S., Pollak, R. (1996), "Bargaining and distribution in marriage”, Journal of Economic Perspectives, 10-4, 139-158.

Lundberg, S., Pollak, R., Wales, T. (1996), “Do husbands and wives pull their resources?”, Journal of Human Resources, 32-3, 463-4.

Mansour, H., McKinnish T. (2014), "Who marries differently-aged spouses? Ability, education, occupation, earnings, and appearance”, The Review of Economics and Statistics, forthcoming. 
Negrusa, B., Oreffice, S. (2010), “Quality of available mates, education, and household labor supply”, Economic Inquiry, 48-3, 558-574.

Oreffice, S. (2011), “Sexual orientation and household decision making: Same-sex couples' balance of power and labor supply choices”, Labour Economics, 18-2, 145-158.

Oreffice, S. (2007), “Did the legalization of abortion increase women's household bargaining power? Evidence from labor supply”, Review of Economics of the Household, 5-2, 181-207.

Oreffice, S., Quintana-Domeque, C. (2012), “Fat spouses and hours of work: are body and Pareto weights correlated?”, IZA Journal of Labor Economics, 1:6.

Rangel, M. (2006), “Alimony rights and intra-household allocation of resources. Evidence from Brazil”, Economic Journal, 116, 627-658.

Ruggles, S., Alexander, T., Genadek, K., Goeken, R., Schroeder, M.B., Sobek, M. (2010), “Integrated Public Use Microdata Series: Version 5.0 [Machine-readable database]”, University of Minnesota.

Schultz, T.P. (1990), “Testing the neoclassical model of family labor supply and fertility”, Journal of Human Resources, 25, 599-634.

Thomas, D. (1990), “Intra-Household Resource Allocation: An Inferential Approach”, Journal of Human Resources, 25, 635-664.

Udry, C. (1996), “Gender, agricultural production, and the theory of the household”, Journal of Political Economy, 104-5, 1010-1046. 


\begin{tabular}{|c|c|c|c|c|c|c|c|c|c|c|c|}
\hline & \multicolumn{4}{|c|}{ All Couples } & \multicolumn{4}{|c|}{ US-born Couples } & \multicolumn{3}{|c|}{ Foreign-born Couples } \\
\hline & \multicolumn{2}{|c|}{ Husbands } & \multicolumn{2}{|c|}{ Wives } & \multicolumn{2}{|c|}{ Husbands } & \multicolumn{2}{|c|}{ Wives } & \multicolumn{2}{|c|}{ Husbands } & Wives \\
\hline Variable & mean & std. dev & mean $s$ & std. dev & mean & std. dev & mean $s$ & std. dev & mean & tdd. dev & mean std. dev \\
\hline Age_diff & 2.06 & 4.42 & 2.06 & 4.42 & 1.98 & 4.23 & 1.98 & 4.23 & 2.73 & 4.59 & 2.73 \\
\hline Y_diff & 1953 & 13222 & 1953 & 13222 & 2002 & 13851 & 2002 & 13851 & 1334 & 11525 & 133411525 \\
\hline Hours worked* & 2219 & 611 & 1718 & 708 & 2247 & 596 & 1713 & 707 & 2078 & 674 & 1676 \\
\hline Log of wage* & 2.89 & .656 & 2.54 & .66 & 2.93 & .64 & 2.55 & .64 & 2.71 & .76 & 2.43 \\
\hline Age & 43.01 & 10.05 & 40.9 & 9.74 & 43.42 & 10.13 & 41.43 & 9.83 & 42.84 & 9.77 & 40.11 \\
\hline Education & 13.46 & 2.51 & 13.49 & 2.33 & 13.64 & 2.22 & 13.66 & 2.05 & 12.22 & 4.31 & 12.14 \\
\hline Couple's non-labor income Y & 4125 & 15291 & 4125 & 15291 & 4228 & 16005 & 4228 & 16005 & 2835 & 14016 & 283514016 \\
\hline Number of children & 1.26 & 1.16 & 1.26 & 1.16 & 1.18 & 1.12 & 1.18 & 1.12 & 1.76 & 1.31 & 1.76 \\
\hline \multirow[t]{3}{*}{ Number of observations } & \multicolumn{2}{|l|}{439660} & \multicolumn{2}{|l|}{439660} & \multicolumn{2}{|l|}{407181} & \multicolumn{2}{|l|}{407181} & \multicolumn{2}{|l|}{32479} & 32479 \\
\hline & \multicolumn{4}{|c|}{$\begin{array}{l}\text { Foreign-born Couples } \\
\text { with different culture from US }\end{array}$} & \multicolumn{4}{|c|}{$\frac{\text { Foreign-born Couples }}{\text { with some what similar culture to US }}$} & \multicolumn{3}{|c|}{$\begin{array}{c}\text { Foreign-born Couples } \\
\text { with very similar culture to US }\end{array}$} \\
\hline & \multicolumn{2}{|c|}{ Heads } & \multicolumn{2}{|c|}{ Partners } & \multicolumn{4}{|c|}{$\begin{array}{ll}\text { Heads } & \text { Partners } \\
\end{array}$} & \multicolumn{3}{|c|}{ Husbands $\quad$ Wives } \\
\hline Variable & \multicolumn{2}{|c|}{ mean std. dev } & \multicolumn{2}{|c|}{ mean std. dev } & \multicolumn{2}{|c|}{ mean std. dev } & \multicolumn{2}{|c|}{ mean std. dev } & \multicolumn{2}{|c|}{ mean std. dev } & mean std. dev \\
\hline Age_diff & 2.9 & 4.59 & 2.9 & 4.59 & 2.89 & 4.65 & 2.89 & 4.65 & 2.15 & 4.51 & 2.15 \\
\hline Y_diff & 1099 & 9689 & 1099 & 9689 & 1315 & 12151 & 1315 & 12151 & 2061 & 14991 & 206114991 \\
\hline Hours worked* & 2056 & 689 & 1599 & 756 & 2101 & 665 & 1746 & 732 & 2109 & 641 & 1789 \\
\hline Log of wage* & 2.62 & .76 & 2.3 & .74 & 2.75 & .77 & 2.49 & .74 & 2.91 & .71 & 2.68 \\
\hline Age & 41.4 & 9.80 & 38.49 & 9.3 & 43.56 & 9.24 & 40.68 & 8.89 & 45.88 & 9.52 & 43.73 \\
\hline Education & 11.31 & 4.59 & 11.28 & 4.28 & 13.09 & 4.03 & 12.78 & 3.73 & 13.66 & 3.04 & 13.73 \\
\hline Couple's non-labor income Y & 2202 & 12111 & 2202 & 12111 & 3277 & 14792 & 3277 & 14792 & 4045 & 17495 & 404517495 \\
\hline Number of children & 1.97 & 1.39 & 1.97 & 1.39 & 1.54 & 1.13 & 1.54 & 1.13 & 1.44 & 1.18 & 1.44 \\
\hline Number of observations & 17533 & & 17533 & & 8009 & & 8009 & & 6937 & & 6937 \\
\hline
\end{tabular}


Table 2. Estimation of the Labor Supply Regressions of US-born and Foreign-born Married Couples

$\begin{array}{llll}\text { All Couples } & \text { US-bom Couples } & \text { Foreign-born Couples } \\ & \end{array}$

Husbands Wives Husbands Wives Husbands Wives

$\begin{array}{lllll}(1) & \text { (2) } & \text { (3) } & \text { (4) } & \text { (5) }\end{array}$

\begin{tabular}{|c|c|c|c|c|c|c|}
\hline Age_diff & $\begin{array}{l}-2.10 * * * \\
(.323)\end{array}$ & $\begin{array}{l}1.11 \text { *** } \\
(.270)\end{array}$ & $\begin{array}{l}-2.42 * * * \\
(.354)\end{array}$ & $\begin{array}{l}1.682 * * * \\
(.284)\end{array}$ & $\begin{array}{l}-2.31 \\
(7.86)\end{array}$ & $\begin{array}{l}-.366 \\
(.952)\end{array}$ \\
\hline Y_diff & $\begin{array}{l}-.0015 * * * \\
(.0001)\end{array}$ & ${ }_{(.0006)}^{.01 * * *}$ & $\begin{array}{l}-.0017 * * * \\
(.0001)\end{array}$ & $\left(_{(.0006)}^{.01}{ }^{* * *}\right.$ & $\begin{array}{r}.0001 \\
(.0003)\end{array}$ & ${ }^{.01}{ }^{* * *}$ \\
\hline Couple's non-labor income Y & $\begin{array}{l}-.0011^{* * *} \\
(.0002)\end{array}$ & $\begin{array}{l}-.012 * * * \\
(.0005)\end{array}$ & $\begin{array}{l}-.002 * * * \\
(.0001)\end{array}$ & $\begin{array}{l}-.012 * * * \\
(.0006)\end{array}$ & $\begin{array}{l}.002 * * * \\
(.0002)\end{array}$ & $\begin{array}{l}-.012 * * * \\
(.0004)\end{array}$ \\
\hline Log of wage of husband & $\begin{array}{c}-111.41 * * * \\
(6.22)\end{array}$ & $\begin{array}{l}-92.27 * * * \\
(3.13)\end{array}$ & $\begin{array}{c}-106.33 * * * \\
(5.91)\end{array}$ & $\begin{array}{c}-100.58 * * * \\
(3.47)\end{array}$ & $\begin{array}{c}-154.98 * * * \\
(8.20)\end{array}$ & $\begin{array}{l}-57.35 * * * \\
(7.95)\end{array}$ \\
\hline Log of wage of wife & $\begin{array}{l}-10.55^{* * *} \\
(2.23)\end{array}$ & $\begin{array}{l}-423.60 * * * \\
(10.90)\end{array}$ & $\begin{array}{l}14.72 \text { *** } \\
(2.48)\end{array}$ & $\begin{array}{l}-408.19 * * * \\
(14.81)\end{array}$ & $\begin{array}{l}-7.96 \\
(6.56)\end{array}$ & $\begin{array}{l}-502.7 * * * \\
(18.35)\end{array}$ \\
\hline Own Age & $\begin{array}{l}-2.32 * * * \\
(.33)\end{array}$ & $\begin{array}{l}1.36 * * * \\
(.278)\end{array}$ & $\begin{array}{l}-3.35 * * * \\
(.37)\end{array}$ & $\begin{array}{l}.405 \\
(.27)\end{array}$ & $\begin{array}{r}.391 \\
(.915)\end{array}$ & $\begin{array}{l}6.86 * * * \\
(.389)\end{array}$ \\
\hline Education of husband & $\begin{array}{l}37.17 * * * \\
(.542)\end{array}$ & $\begin{array}{l}-7.58 * * * \\
(1.69)\end{array}$ & $\begin{array}{l}37.46 * * * \\
(.69)\end{array}$ & $\begin{array}{c}-12.48 * * * \\
(.66)\end{array}$ & $\begin{array}{l}25.82 * * * \\
(1.29)\end{array}$ & $\begin{array}{l}4.71 * * \\
(2.36)\end{array}$ \\
\hline Education of wife & $\begin{array}{l}12.29 * * * \\
(.833)\end{array}$ & $\begin{array}{l}16.16 * * * \\
(1.28)\end{array}$ & $\begin{array}{l}9.68 * * * \\
(.69)\end{array}$ & $\begin{array}{l}15.14^{* * *} \\
(1.52)\end{array}$ & $\begin{array}{l}10.62 * * * \\
(1.59)\end{array}$ & $\begin{array}{l}16.51 \text { *** } \\
(1.99)\end{array}$ \\
\hline Number of children & $\begin{array}{l}22.65 * * * \\
(2.14)\end{array}$ & $\begin{array}{l}-67.74 * * * \\
(2.92)\end{array}$ & $\begin{array}{l}31.03 * * * \\
(1.41)\end{array}$ & $\begin{array}{l}-80.35 * * * \\
(3.49)\end{array}$ & $\begin{array}{r}7.35 \\
(5.14)\end{array}$ & $\begin{array}{l}-18.26 * * * \\
(3.48)\end{array}$ \\
\hline Number of observations & 439660 & 439660 & 407181 & 407181 & 32479 & 32479 \\
\hline
\end{tabular}


Table 3. Estimation of the Labor Supply Regressions of Foreign-Born Married Couples by Culture

\begin{tabular}{ll}
$\begin{array}{l}\text { Foreign-born Couples } \\
\text { with different culture from US }\end{array}$ & $\begin{array}{c}\text { Foreign-bom Couples } \\
\text { with somewhat similar culture to US }\end{array}$ \\
\hline
\end{tabular}

Foreign-bom Couples

\section{Husbands Wives}

(7) (8)

Age_diff

Y_diff

Couple's non-labor income Y

Log of wage of husband

Log of wage of wife

Own Age

Education of husband

Education of wife

Number of children

$$
-1.82
$$

(1.41)

$-.001$

(.001)

.002

(.001)

-204.3 ***

(57.53)

$-61.02$

(71.03)

$7.04 * * *$

(1.63)

$17.82 * * *$

(2.53)

$8.85 * * *$

(2.53)

1.57

(8.03)

\section{Husbands}

(9)

$\begin{array}{cc}-4.63 & 3.87 \\ (3.81) & (3.24) \\ -.00003 & -.0007 \\ (.002) & (.003) \\ .003 & .001 \\ (.002) & (.002) \\ -203.9 * * & -107.7 \\ (87.48) & (76.48) \\ -15.31 & -166.3 * \\ (86.68) & (95.5) \\ 3.23 & 8.14 \text { *** } \\ (2.34) & (2.61) \\ 18.26 * * * & -2.79 \\ (3.63) & (5.06) \\ 9.55 * * & 14.07 \text { ** } \\ (4.79) & (6.06) \\ 8.26 & -22.66 \text { *** } \\ (14.21) & (8.16)\end{array}$

with very similar culture to US
Husbands

(11)

$-3.73 *$
$(1.99)$
$-.001 * *$
$(.0007)$

$.003 * * *$

$(.0007)$

$-160.73$

(114)

$-118.6$

(152.9)

$-.144$

(1.63)

$21.56 * * *$

(3.99)

$-7.36 *$

(4.46)

$-17.14 * *$

(6.45)
Wives

(12)

$6.90 * * *$

(2.11)

$.034 * * *$

(.002)

$-.033 * * *$

(.002)

311.93

(249.9)

$-854 * * *$

(290.5)

$4.43 * *$

(1.87)

$-5.04$

(5.69)

(5.48)

$-21.74 * * *$

(6.26)
$-12.12 * *$

Number of observations

17533

8009

8009

6937

6937 
Table 4. Estimation of the Labor Supply Regressions of Foreign-Born Married Couples with interactions of years spent in the US

\section{Foreign-born Couples with different culture from US}

\section{Husbands Wives}

(1) (2)

Age_diff

Y_diff

Own years spent in the US

$\begin{array}{cl}9.35 * * * & 6.19 * * * \\ (1.72) & (.675)\end{array}$

Age_diff interacted years US

.163

(.226)

$-3.94$

(3.22)

-7.22
$(2.91)$

$-.0003$

$(.002)$

(.675)

$.668 * * *$

(.141)
$-.035$

(.369)

$8.51 * *$

(1.57)

$7.98 * * *$

(1.64)

$.011 * * *$

.003

(0.002)

(4)

(6.08)

(6.81)

Foreign-born Couples

with very similar culture to US

Husbands
(5)
$-3.74 *$
$(2.19)$

$-.0013 * * *$
$(.0002)$

Wives

(6)

$1.97 * *$

(3.35)

(.002)

(.002)

.263

(.964)

(1.32)

$-.191$

.392 *

(.210)

Y_diff interacted years US

$$
\begin{array}{lr}
.00002 & .0001 \\
(.0001) & (.0001)
\end{array}
$$$$
-.0002
$$$$
\text { (.0003) }
$$

$$
-.0008 * * *
$$

Number of observations

8009

8009

6937

6937

$*^{* *} ;{ }^{* *}$ significant at $10 \%, 5 \%$ and $1 \%$. Estimated coefficients, robust standard errors (in parenthesis) clustered by state. 
Table 5. Estimation of the Labor Supply Regressions of All Married Couples with Gender Role Variable and its Interactions

\begin{tabular}{|c|c|c|}
\hline & $\begin{array}{c}\text { Husbands } \\
\text { (1) }\end{array}$ & $\begin{array}{c}\text { Wives } \\
(2)\end{array}$ \\
\hline Age_diff & $\begin{array}{l}-3.49 * * * \\
(1.08)\end{array}$ & $\begin{array}{l}3.71 \text { *** } \\
(1.07)\end{array}$ \\
\hline Y_diff & $\begin{array}{l}-.0034 * * * \\
(.0005)\end{array}$ & $\begin{array}{l}.0089 * * * \\
(0.0007)\end{array}$ \\
\hline Gender role variable & $\begin{array}{l}-2.48 * * * \\
(.255)\end{array}$ & $\begin{array}{l}-1.09 * * * \\
(.399)\end{array}$ \\
\hline Age_diff interacted gender role variable & $\begin{array}{c}.039 * \\
(.020)\end{array}$ & $\begin{array}{l}-.0588 * * \\
(.024)\end{array}$ \\
\hline Y_diff interacted gender role variable & $\begin{array}{l}.00004 * * * \\
(.0003)\end{array}$ & $\begin{array}{l}-.00003 \text { *** } \\
(.000007)\end{array}$ \\
\hline Number of observations & 439660 & 439660 \\
\hline
\end{tabular}


Table 6. Estimation of the Labor Supply Regressions of Second- \& Higher-generation Immigrant Married Couples by Ancestry

\begin{tabular}{|c|c|c|c|c|c|c|}
\hline & \multicolumn{2}{|c|}{ All Couples } & \multicolumn{2}{|c|}{ US Ancestry Couples } & \multicolumn{2}{|c|}{ Foreign Ancestry Couples } \\
\hline & $\begin{array}{c}\text { Husbands } \\
\text { (1) } \\
\end{array}$ & $\begin{array}{c}\text { Wives } \\
(2)\end{array}$ & $\begin{array}{c}\text { Husbands } \\
\text { (3) } \\
\end{array}$ & $\begin{array}{c}\text { Wives } \\
(4)\end{array}$ & $\begin{array}{c}\text { Husbands } \\
\text { (5) } \\
\end{array}$ & $\begin{array}{c}\text { Wives } \\
(6) \\
\end{array}$ \\
\hline Age_diff & $\begin{array}{l}-2.00 * * * \\
(.344)\end{array}$ & $\begin{array}{l}1.37 * * * \\
(.275)\end{array}$ & $\begin{array}{l}-1.15 * \\
(.699)\end{array}$ & $\begin{array}{l}1.89 * \\
(1.04)\end{array}$ & $\begin{array}{l}-2.76 * * * \\
(.641)\end{array}$ & $\begin{array}{c}2.36 * * * \\
(.446)\end{array}$ \\
\hline Y_diff & $\begin{array}{l}-.002 * * * \\
(.0001)\end{array}$ & $\begin{array}{l}.010 * * * \\
(.0006)\end{array}$ & $\begin{array}{l}-.002 * * * \\
(.0006)\end{array}$ & $\begin{array}{l}0.01 \\
(.0007)\end{array}$ & $\begin{array}{l}-.0018 * * * \\
(.0002)\end{array}$ & $\begin{array}{l}.010 * * * \\
(.0006)\end{array}$ \\
\hline \multirow[t]{3}{*}{ Number of observations } & 462076 & 462076 & 34001 & 34001 & 121712 & 121712 \\
\hline & \multicolumn{2}{|c|}{$\begin{array}{c}\text { Foreign Ancestry Couples } \\
\text { with different culture from US }\end{array}$} & \multicolumn{2}{|c|}{$\begin{array}{l}\text { Foreign Ancestry Couples } \\
\text { with somewhat similar culture to US } \\
\end{array}$} & \multicolumn{2}{|c|}{$\begin{array}{c}\text { Foreign Ancestry Couples } \\
\text { with very similar culture to US }\end{array}$} \\
\hline & $\begin{array}{c}\text { Husbands } \\
(7) \\
\end{array}$ & $\begin{array}{c}\text { Wives } \\
(8)\end{array}$ & $\begin{array}{c}\text { Husbands } \\
(9) \\
\end{array}$ & $\begin{array}{c}\text { Wives } \\
(10) \\
\end{array}$ & $\begin{array}{c}\text { Husbands } \\
(11) \\
\end{array}$ & $\begin{array}{c}\text { Wives } \\
(12)\end{array}$ \\
\hline Age_diff & $\begin{array}{l}-3.61 \\
(5.53)\end{array}$ & $\begin{array}{l}-1.81 \\
(4.93)\end{array}$ & $\begin{array}{r}6.79 \\
(8.43)\end{array}$ & $\begin{array}{l}-5.80 \\
(9.50)\end{array}$ & $\begin{array}{l}-2.86 * * * \\
(.638)\end{array}$ & $\begin{array}{c}2.18 * * * \\
(.456)\end{array}$ \\
\hline Y_diff & $\begin{array}{l}-.005 * * \\
(.002)\end{array}$ & $\begin{array}{l}.0008 \\
(.002)\end{array}$ & $\begin{array}{l}-.002 * * \\
(.0008)\end{array}$ & $\begin{array}{r}.00000 \\
(.002)\end{array}$ & $\begin{array}{l}-.002 * * * \\
(.0002)\end{array}$ & $\begin{array}{l}.010 * * * \\
(.0006)\end{array}$ \\
\hline Number of observations & 3272 & 3272 & 1788 & 1788 & 116652 & 116652 \\
\hline
\end{tabular}

